\title{
塗膜の付着に及ぼす溶剤組成の影響
}

\author{
千田七 郎*・植木憲 二** \\ * アトム化学塗料（株）埼玉工場 \\ 加須市加須工業団地内 \\ ** 職業訓練大学校 \\ 相模原市相原 1960
}

\section{The Effect of Solvent Composition on the Adhesive Strength of Coating Films}

\author{
Shichiro ChidA* and Kenji UeKr** \\ *Atom Chemical Paint Co. Ltd. \\ Kasu, Kasushi, Saitama \\ **Institution of Vocational Training \\ Aihara 1960, Sagamihara-shi, Kanagawa
}

\begin{abstract}
Relations between adhesive strength of coating films and properties of solvents, such as solubility and rate of evaporation, were studied.

Three typical coatings (NC lacquer, alkyd resin paint and amino-alkyd coating) were selected, and the samples were prepared in various solvent composition.

A series of the samples have various solvent-diluent ratio, and another series have different evaporation rate. Adhesive strength of the films was determined by the Adherometer, cross cut test and spiral cut test. Meanwhile, stress-strain of the films was measured and general paint film tests were carried.

Results are summarized as follows.

(1) It was generally found that with poor solvent systems, adhesive properties decreased. This phenomenon was remarkable with air drying type coating films (NC lacqer and alkyd resin films), but not so clear with baking type films (amino-alkyd coatings).

(2) With fast evaporative solvents, adhesive properties decreased.

(3) The results described above were discussed from the viewpoint of the state of vehicle polymer in the solutions and wettability of substrate surfaces by the solutions.
\end{abstract}

要 旨

蒤膜の付着性に扣よぼす溶剤組成の影響を明らかにす

る目的で, 典型的溶剤形塗料 3 種（ニトロセルロースラ

ッカー・アルキド樹脂塗料・アミノアルキド樹脂烝料)

を選び, 付着性と溶剂の溶解力ならびに揮発速度との関

昭和 50.2.3 受理
係を検討した。付着強さの評価にはアドへロメーター・・ ゴバン目执よび描画試験機を用いた。同時に, Instron 形万能材料試験機による塗膜の応力〜ひずみ関係測定お よび JIS 法（K 5400）による塗料一般試験も行なった。 実験結果をまとめると次のようである。

（1）溶剂組成が貪溶媒系の塗料注ぞ，一般に付着性 は低下する。この傾向は自然乾燥形塗料（ニトロセルロ 
一スラッカー・アルキド樹脂塗料）では顕著であるが， 焼付塗料（アミノアルキド樹脂塗料）では不明確であっ た。

（2）溶剤の揮発速度が大きい系の塗料注ど, 一般に 付着性は低下する。

（3）以上の結果について考察した。

$$
\text { 1. は じめに }
$$

塗料の理想的姿の 1 つは無溶剤形であるので，公害な らびに省資源対策の観点から，ハイソリッド形塗料・無 溶剂形塗料・粉体塗料など新しい塗料が最近非常に注目 されている。しかし, 古くからある溶剂形塗料は作業 性・塗面状態・経済性などに捨てがたい特長をもってい るので，相変わらず塗料の主流を占めている。

溶剂組成は塗膜形成過程（乾燥）・作業性・塗面状態・ 上塗り適性・塗膜の機械的諸性質 - 塗料の安定性 - 顔料 分散などに大きな役割りを演じる。したがって，これら の性質に括よぼす影響については多数報告されている。 最近, Funke ${ }^{1)}$, 日比 ${ }^{2)}$, Gribkova ら ${ }^{3)}$ は塗膜物性に特 よぼす溶剤組成の影響について興味深い報告を発表し， 希釈剤の配合は単に増量または経済的利点からばかりで
なく，塗膜物性の改善の観点からも重要であることを明 らかにした。溶剤組成は以上のような塗膜バルクの物性 に大きな影響を与えるばかりでなく，付着性にも影響す ることが予想されるが，それについての報告はほとんぞ ない。

われわれは塗膜の付着性に括よぼす溶剂組成の影響に ついて知見を得る目的で, 現在広く使用されている典型 的溶剤形塗料（ニトロセルロースラッカー・アルキド樹 脂塗料・アミノアルキド樹脂塗料）を選び実験を行なっ た。すなわち, 溶剤の溶解力または揮発速度が一連に異 なる組成の塗料を調製して付着性を評価し, 溶剤組成と 付着強さの関係を明らかにし新しい知見を得たので報告 する。な打付着強さの測定ばかりでなく, 遊離塗膜の応 力〜ひずみ関係と塗料一般試験（JIS 法）も同時に測定 し，結果の考察の資料にした。

\section{2. 試料と試験法}

\section{1 試 料}

（1）二トロセルロース（NC と略す） テッカー 市販の NC およびアルキド樹脂を用い, 次のような固 形分比のラッカークリヤーを調製した。

Table 1. Solvent composition of samples

Solubility

\begin{tabular}{|c|c|c|c|c|c|c|c|c|}
\hline \multirow[b]{2}{*}{ NC Lacquer } & \multirow[b]{2}{*}{$\begin{array}{l}\text { Toluene-BuAc. } \\
\text { Conc. of toluene } \\
\text { (IPA etc. are the same.) }\end{array}$} & \multicolumn{7}{|c|}{ Wt. $\%$ of solvent in total solvent } \\
\hline & & $\begin{array}{c}\text { Clear } \\
\text { Enamel }\end{array}$ & & $\begin{array}{r}11 \\
8\end{array}$ & $\begin{array}{l}28 \\
19\end{array}$ & $\begin{array}{l}46 \\
31\end{array}$ & $\begin{array}{l}64 \\
53\end{array}$ & $\begin{array}{l}66 \\
56\end{array}$ \\
\hline Alkyd Resin & $\begin{array}{l}\text { IPA-Xylene } \\
\text { Conc. of xylene } \\
\text { (MS is the same.) }\end{array}$ & $\begin{array}{l}\text { Medium oil (Linseed) } \\
\text { Long oil (Soya) }\end{array}$ & $\begin{array}{l}\mathrm{C} \\
\mathrm{E} \\
\mathrm{C} \\
\mathrm{E}\end{array}$ & $\begin{array}{l}0 \\
0 \\
0 \\
0\end{array}$ & $\begin{array}{l}14 \\
15 \\
18 \\
21\end{array}$ & $\begin{array}{l}27 \\
31 \\
36 \\
41\end{array}$ & $\begin{array}{l}42 \\
48 \\
54 \\
61\end{array}$ & $\begin{array}{l}52 \\
50 \\
69 \\
70\end{array}$ \\
\hline $\begin{array}{l}\text { Aminoalkyd } \\
\text { Resin }\end{array}$ & $\begin{array}{l}\mathrm{BuOH} .-\mathrm{Xylene} \\
\text { Conc. of } \mathrm{BuOH} \text {. }\end{array}$ & $\begin{array}{l}\text { Clear } \\
\text { Enamel }\end{array}$ & & $\begin{array}{l}8 \\
4\end{array}$ & $\begin{array}{l}19 \\
23\end{array}$ & $\begin{array}{l}28 \\
41\end{array}$ & $\begin{array}{l}39 \\
59\end{array}$ & $\begin{array}{l}47 \\
77\end{array}$ \\
\hline Evaporation $\mathrm{R}$ & & & & & & & & \\
\hline NC Lacquer & $\begin{array}{c}\text { EAc. }- \text { BuAc. } \\
\text { Conc. of EAc. } \\
\text { (IPA etc. are the same.) }\end{array}$ & $\begin{array}{l}\text { Clear } \\
\text { Enamel }\end{array}$ & & $\begin{array}{l}0 \\
0\end{array}$ & $\begin{array}{l}17 \\
12\end{array}$ & $\begin{array}{l}34 \\
26\end{array}$ & $\begin{array}{l}49 \\
35\end{array}$ & $\begin{array}{l}63 \\
53\end{array}$ \\
\hline Alkyd Resin & $\begin{array}{l}\text { Gasoline-MS. } \\
\text { Conc. of gasoline }\end{array}$ & $\begin{array}{l}\text { Medium oil (Linseed) } \\
\text { Long oil (Soya) }\end{array}$ & $\begin{array}{l}\mathrm{C} \\
\mathrm{E} \\
\mathrm{C} \\
\mathrm{E}\end{array}$ & $\begin{array}{l}0 \\
0 \\
0 \\
0\end{array}$ & $\begin{array}{l}16 \\
18 \\
18 \\
20\end{array}$ & $\begin{array}{l}31 \\
36 \\
38 \\
39\end{array}$ & $\begin{array}{l}46 \\
53 \\
52 \\
60\end{array}$ & $\begin{array}{l}66 \\
70 \\
72 \\
80\end{array}$ \\
\hline Aminoalkyd & $\left|\begin{array}{c}\text { Gasoline-MS. } \\
\text { Conc. of gasoline } \\
(\mathrm{BuOH} . \text { and xylene are the same. })\end{array}\right|$ & $\begin{array}{l}\text { Clear } \\
\text { Enamel }\end{array}$ & & $\begin{array}{l}0 \\
0\end{array}$ & $\begin{array}{l}11 \\
20\end{array}$ & $\begin{array}{l}20 \\
40\end{array}$ & $\begin{array}{l}29 \\
60\end{array}$ & $\begin{array}{l}39 \\
79\end{array}$ \\
\hline
\end{tabular}

C : Clear E : Enamel 


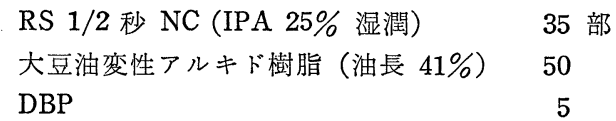

ラッカーエナメルは市販のラッカー白エナメルに対 し，固形分比で上記大豆油变性アルキド樹脂を $20 \%$ 添 加して試料とした。

\section{（2）アルキド樹脂塗料}

市販のあまに油変性アルキド樹脂（油長 $52 \%$ ) および 大豆油変性アルキド樹脂（油長 $65 \%$ ）飞対し，それぞれ ドライヤーを添加してアルキド樹脂ワニスを調製した。 ドライヤーの組成は樹脂固形分に対し， $6 \%$ ナフテン酸 コバルト $0.5 \%+24 \%$ ナフテン酸鉛 $0.5 \%$ とした。

上記ワニスの固形分 45 部に対しルチル形チタン白 55
部を加光，ロール練摩後ワニスと同様のドライヤーを添 加して，あまに油変性アルキド樹脂白エナメルと大豆油 変性アルキド樹脂白エナメルを調製した。

（3）アミノアルキド樹脂塗料

市肘のブチル化メラミン樹脂 3 部と大豆油変性アルキ ド樹脂（油長 41\%）７部（いずれる固形分比）を混合し て，アミノアルキド樹脂クリヤーを調製した。

上記クリヤーの固形分 45 部に対しルチル形チタン白 55 部を混合，ロール練摩してアミノアルキド樹脂白エ ナメルを調製した。

これら各試料の溶剤組成を表-1 亿示す。

\section{2 試験片の調製之試験法}

（1） 付着強さ測定

Table 2. Effect of solubility of solvent on coating properties

\begin{tabular}{|c|c|c|c|c|c|c|}
\hline Lacquer & Conc. of toluene $(\%)$ & 11 & 28 & 46 & 64 & 66 \\
\hline \multirow[t]{3}{*}{ Clear } & Pencil test & $5 \mathrm{H}$ & $4 \mathrm{H}$ & $2 \mathrm{H}$ & $3 \mathrm{H}$ & $3 \mathrm{H}$ \\
\hline & Impact test & $x$ & $x$ & $x$ & $x$ & $x$ \\
\hline & Bending test & $x$ & $x$ & $x$ & $x$ & $x$ \\
\hline \multirow[t]{4}{*}{ Enamel } & Conc. of toluene (\%) & 8 & 19 & 31 & 53 & 56 \\
\hline & Pencil test & H B & $\mathrm{H} \mathrm{B}$ & H B & $\mathrm{H} \mathrm{B}$ & $\mathrm{H} \mathrm{B}$ \\
\hline & Impact test & $\triangle$ & $\triangle$ & 0 & $\bigcirc$ & $\triangle$ \\
\hline & Bending test & 0 & $\triangle$ & 0 & $\bigcirc$ & 0 \\
\hline Alkyd & Conc. of IPA $(\%)$ & 0 & 14 & 27 & 42 & 52 \\
\hline Linseed medium & Pencil test & $\mathrm{H} \mathrm{B}$ & $\mathrm{H}$ & $\mathrm{H}$ & $3 \mathrm{H}$ & $\mathrm{H}$ \\
\hline \multirow[t]{2}{*}{ Clear } & Impact test & $\times$ & $\times$ & $x$ & $x$ & $\triangle$ \\
\hline & Bending test & 0 & 0 & $\bigcirc$ & 0 & 0 \\
\hline \multirow[t]{4}{*}{ Enamel } & Conc. of IPA $(\%)$ & 0 & 15 & 31 & 48 & 50 \\
\hline & Pencil test & $3 \mathrm{H}$ & $3 \mathrm{H}$ & $3 \mathrm{H}$ & $\mathrm{F}$ & $\mathrm{F}$ \\
\hline & Impact test & $\times$ & $\times$ & $\times$ & $x$ & $x$ \\
\hline & Bending test & $x$ & $x$ & $x$ & $x$ & $x$ \\
\hline Soya long & Conc. of IPA (\%) & 0 & 18 & 36 & 54 & 69 \\
\hline \multirow[t]{3}{*}{ Clear } & Pencil test & $\mathrm{H}$ & $\mathrm{F}$ & $\mathrm{F}$ & H B & $\mathrm{F}$ \\
\hline & Impact test & $\triangle$ & $\triangle$ & $x$ & $\triangle$ & $x$ \\
\hline & Bending test & $\bigcirc$ & 0 & $\bigcirc$ & $\bigcirc$ & 0 \\
\hline \multirow[t]{4}{*}{ Enamel } & Conc. of IPA $(\%)$ & 0 & 21 & 41 & 61 & 71 \\
\hline & Pencil test & $\mathrm{F}$ & $\mathrm{F}$ & $\mathrm{F}$ & $\mathrm{F}$ & $\mathrm{F}$ \\
\hline & Impact test & $x$ & $x$ & $x$ & $x$ & $x$ \\
\hline & Bending test & 0 & $\triangle$ & $\triangle$ & $\triangle$ & $x$ \\
\hline Aminoalkyd & Conc. of $\mathrm{BuOH}(\%)$ & 8 & 19 & 28 & 39 & 47 \\
\hline \multirow[t]{3}{*}{ Clear } & Pencil test & $2 \mathrm{H}$ & $2 \mathrm{H}$ & $3 \mathrm{H}$ & $2 \mathrm{H}$ & $2 \mathrm{H}$ \\
\hline & Impact test & $\triangle$ & $\triangle$ & $\triangle$ & $\triangle$ & $\triangle$ \\
\hline & Bending test & $\times$ & $\times$ & $\times$ & $x$ & $x$ \\
\hline \multirow[t]{4}{*}{ Enamel } & Conc. of $\mathrm{BuOH}(\%)$ & 4 & 23 & 41 & 59 & 77 \\
\hline & Pencil test & $2 \mathrm{H}$ & $2 \mathrm{H}$ & $3 \mathrm{H}$ & $3 \mathrm{H}$ & $2 \mathrm{H}$ \\
\hline & Impact test & $\triangle$ & $\triangle$ & $x$ & $\triangle$ & $x$ \\
\hline & Bending test & $\times$ & $x$ & $x$ & $\times$ & $x$ \\
\hline
\end{tabular}


軟鋼板 $(150 \times 70 \times 1 \mathrm{~mm})$ を\#320 と\#400 のサンド ペーパーで研摩, 清浄にした後直ちに各試料を吹付け塗 布した。十分乾燥した塗膜について物性を試験する目的 で, 次のように乾燥硬化して測定用試験片とした。

$\mathrm{NC}$ ラッカー： 2 日間放置 $+45^{\circ} \pm 2^{\circ} \mathrm{C} / 12$ 時間強制 乾燥

アルキド樹脂塗料： 2 日間放置 $+50^{\circ} \pm 2^{\circ} \mathrm{C} / 96$ 時間 強制乾燥

アミノアルキド樹脂塗料： 2 時間セッティング $+80^{\circ} \pm 2^{\circ} \mathrm{C} / 3$ 時間焼付

付着強さの評価にはアドヘロメーター・ゴバン目拉よ び描画試験機を採用した。各試験片につきアドへロメー ター4) では 4 回測定し, その平均值を測定值とした。ゴ バン目試験4) では 4 回測定し，10 点法による評価の平 均值を測定值とした。描画試験 ${ }^{4)}$ では 2 回測定し，10 点法による評価の平均值を測定值とした。

（2）応力〜ひずみ性測定

各試料を溶剤脱脂したブリキ板 $(110 \times 120 \times 0.3 \mathrm{~mm})$ に吹付け塗布し，（1 項と同様に乾燥硬化した後, アマ ルガム法により $10 \times 110 \mathrm{~mm}$ の遊離塗膜をつくった。こ れを応力〜ひずみ測定用塗膜とした。

Instron 形万能材料試験機を用い, 引張速度 $10 \mathrm{~mm} /$

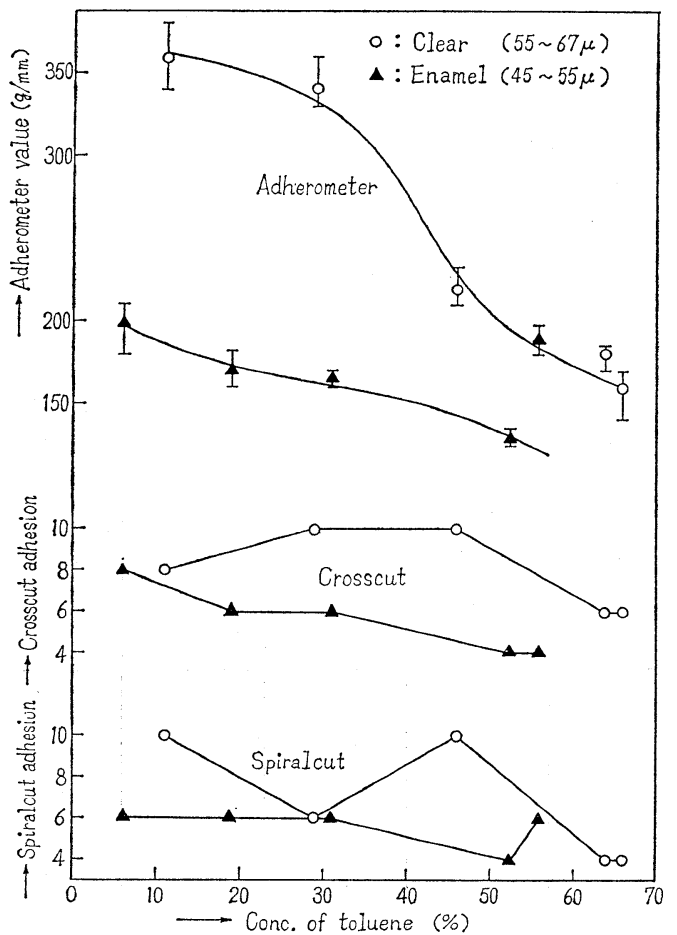

Fig. 1. Effect of solubility of solvent on adhesive property of lacquer films (Toluene-BuAc)
分で引張試験を行ない，応力〜ひずみ曲線を得た。5 回 の測定值を平均した。

（3）塗料一般試験

(1) 項と同様に塗布・乾燥した試験片について, JIS K 5400 塗料一般試験法に準じ，鉛筆引かき試験 (6.14)・ 耐衝撃性 (6.13)・耐屈曲性 (6.15) を試験した。

\section{3. 結 果 と考察}

\section{1 付着に及ぼす溶剤の溶解力の影響}

各種塗膜の付着に执よぼす溶剤の溶解力の影響につい ての実験結果を図-1～3 に示す。塗膜の応力〜ひずみ曲 線から求めた諸物性, たとえば抗張力・伸び・モンジュ ラスなどに及ぼす溶剤の溶解力の影響については，筆者 らの一人がすでに報告2) しているので，アルキド樹脂塗 膜についてのみ参考として図-4に示す。また，塗料一 般試験の結果を表-2 に示す。

図-1〜3 から，系の溶解力が低下するにともない塗膜 の付着性は一般に低下寸ることがわかる。しかも当然予

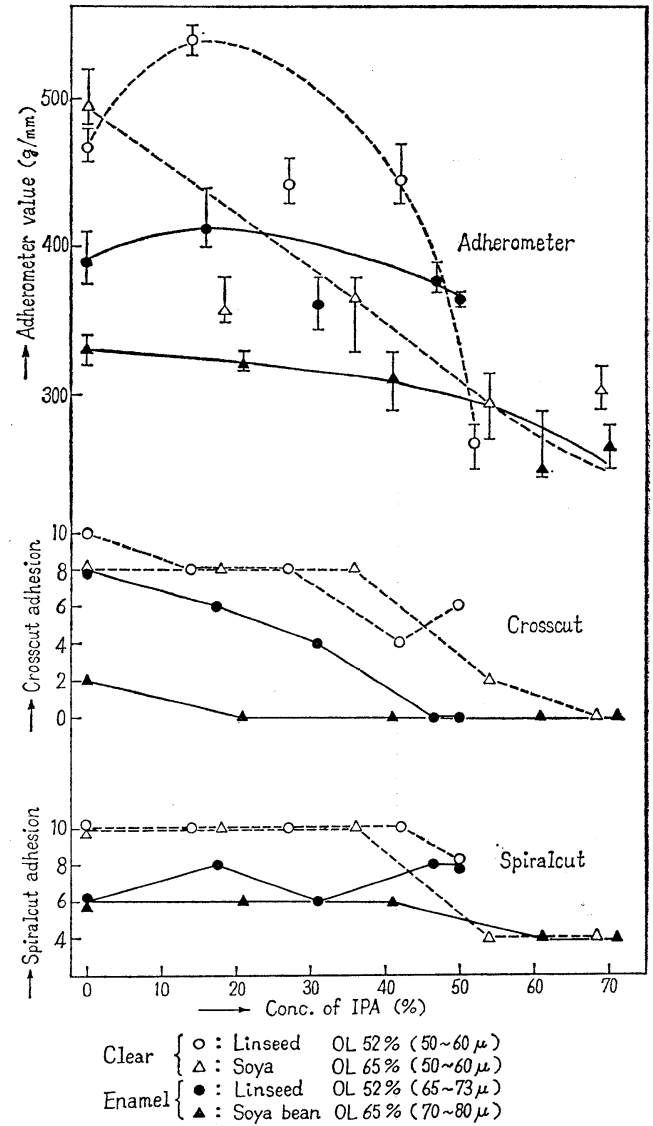

Fig. 2. Effect of solubility of solvent on adhesive property of alkyd paint films (IPA-Xylene) 
想されるように，この傾向は高分子量ポリマー (NC) を 含むラッカー系で最も明瞭であり，アルキド樹脂系がこ れに次ぎ, 溶剤揮発後も焼付過程である程度流動すると 考えられるアミノアルキド樹脂系ではあまり明瞭でな Wo

中油性アルキド樹脂塗料では, 少量の IPA 混合でア ドロヘロメーター付着強さの上昇が見られるが，長油性

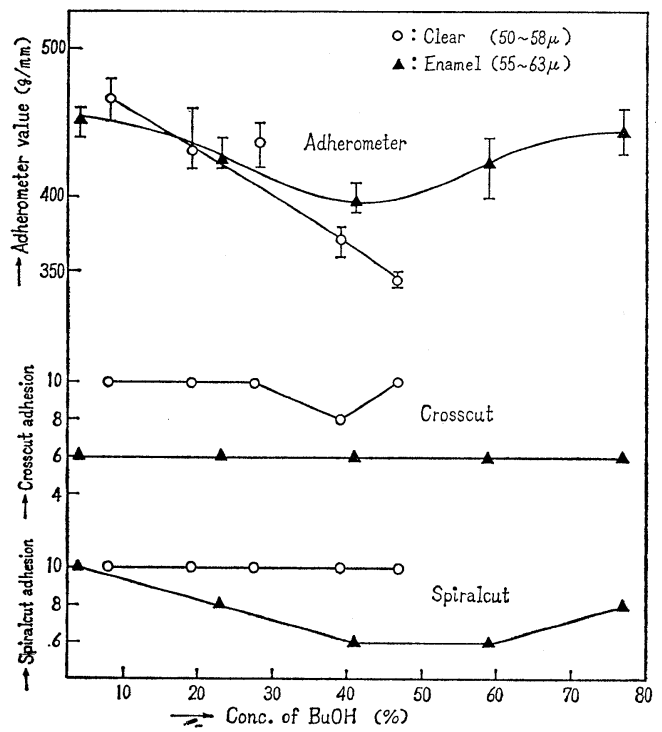

Fig. 3. Effect of solubility of solvent on adhesive property of aminoalkyd film(BuOH-Xylene)

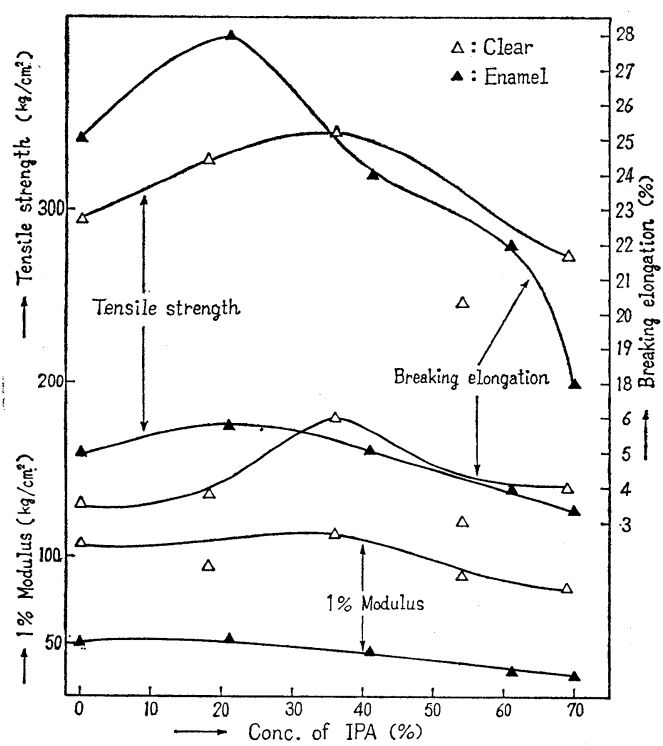

Fig. 4. Effect of solubility of solvent on properties of soya modified alkyd paint films (IPA-Xylene)
アルキド樹脂塗料ではそのような現象は認められない (図-2)。同じ試料についても，測定精度のやや劣るゴン゙ ン目括よび描画試験の結果では，上述の現象は認められ ず IPA 濃度の増大にともない塗膜の付着性は低下す る。中油性アルキド樹脂に見られるこのような例外はア ルキド樹脂の極性が比較的高いめ, 少量の IPA の添加 は，その S.P. 值から予想されるように，系の溶解力を 増大することに基因すると考えられる。

またアミノアルキド樹脂エナメルのアドヘロメーター 特よび描画試験に特いて，ブタノール濃度 $50 \%$ 付近で その付着值がわずかに低下することが認められる（図一 3)。アミノアルキド樹脂塗料はアルキド樹脂（比較的非 極性）とアミノ樹脂（比較的極性）の混合物であるた め, 系の溶解力の考察は単一ビヒクル系のそれに比べ複 雑である。アルキド樹脂に対してはキシャールが，アミ ノ樹脂に対してはブタノールが良溶媒になる。恐らくブ タノール濃度 $50 \%$ 付近は両種の樹脂に対する総合的溶 解力の点からはあまり好ましい溶剤組成でないように思 われる。

以上のような多少の例外はあるにしても，一般的には 溶解力の増大にともない付着性は増大する。その原因と して次の 2 つが考えられる。すなわち,

（1）良溶媒系ではポリマー分子の糸まり状態は貪溶 媒系のそれに比べ比較的ルーズである。したがって，ポ リマー分子の付着活性点（極性基）がポリマー分子内部

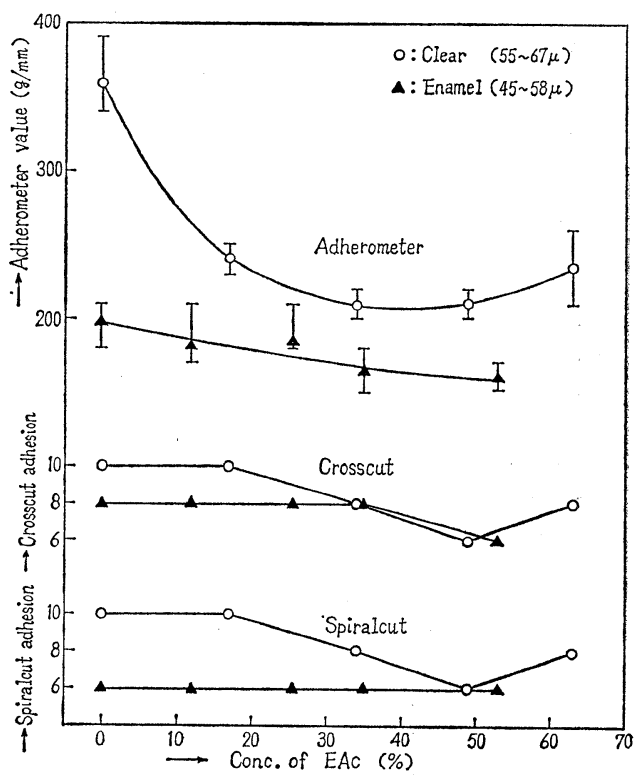

Fig. 5. Effect of evaporation rate of solvent on adhesive property of lacquer films(EAc$\mathrm{BuAc}$ ) 
にとじこめられる確率が少なく，有効な付着活性点が多 いと考光られる。

（2）良溶媒系の溶液粘度は領溶媒系の气れに比べ低 いから，ビヒクルポリマー分子の拡散が容易である。こ のことはポリマーの活性点が被塗物表面の活性点に容易 飞接近することを意味し，有効な付着の確率が大きい。

系の溶解力増大にとるなら付着性の増大は上述の 2 因 子（ポリマーの有効付着活性点の増大と拡散容易）の総 合結果と考学られば，合理的に説明できる。

塗膜の付着性は鉛筆引かき・耐衝撃・耐屈曲試験から も，ある程度評価できることが予想される。しかし，一 部の結果（表-2 のあまに油変性アルキド樹脂エナメル の鉛筆引かき試験）を除き，この実験の溶剤組成範囲内 では, 塗料一般試験法からは有意な結果は認められなか った。

\section{2 付着に及ぼす溶㣚の揮発速度の影響}

各種塗膜の付着に持よぼす溶剤の揮発速度の影響を図

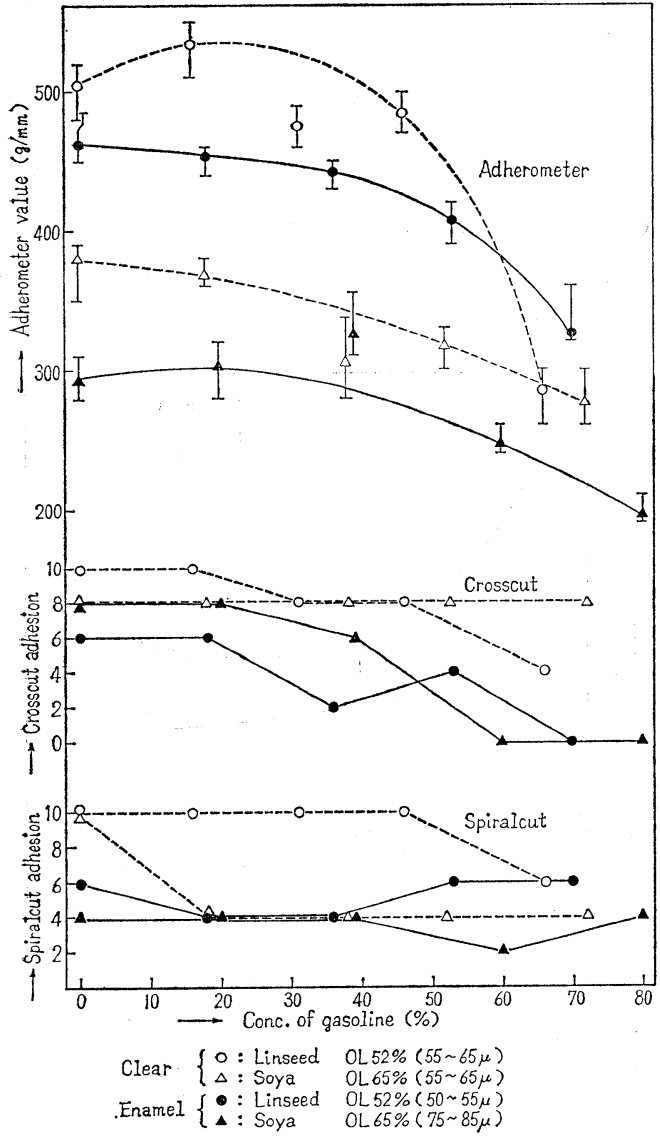

Fig. 6. Effect of evaporation rate of solvent on adhesive property of alkyd paint films (Gasoline-MS)
-5〜7 に示す。塗膜バルクの諸物性に和よぼす影響の一 例（あまに油変性アルキド樹脂塗膜）を図-8 亿示す。 また，一般試験結果を表-3 亿示す。

図-5〜7 から明らかであり，また経験的にも知られて

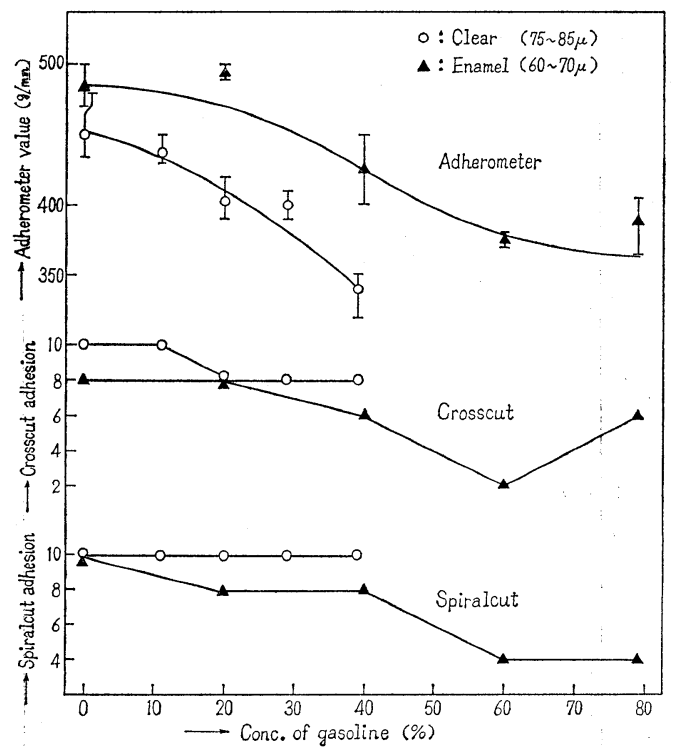

Fig. 7. Effect of evaporation rate of solvent on adhesive property of amino-alkyd film (Gasoline-MS)

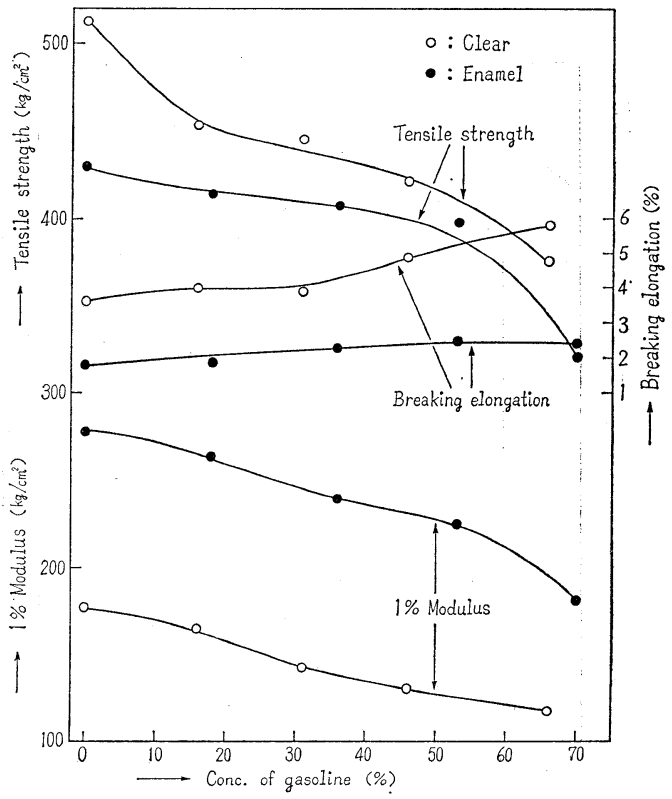

Fig. 8. Effect of evaporation rate of solvent on physical properties of linseed modified alkyd paint films (Gasoline-MS) 
Table 3. Effect of evaporation rate of solvent on coating properties

\begin{tabular}{|c|c|c|c|c|c|c|}
\hline Lacquer & Conc. of EAc (\%) & 0 & 17 & 34 & 49 & 63 \\
\hline \multirow[t]{3}{*}{ Clear } & Pencil test & $5 \mathrm{H}$ & $3 \mathrm{H}$ & $2 \mathrm{H}$ & $3 \mathrm{H}$ & $4 \mathrm{H}$ \\
\hline & Impact test & $\times$ & $\times$ & $\times$ & $\times$ & $\times$ \\
\hline & Bending test & $x$ & $x$ & $x$ & $x$ & $x$ \\
\hline \multirow[t]{4}{*}{ Enamel } & Conc. of EAc (\%) & 0 & 12 & 26 & 35 & 53 \\
\hline & Pencil test & $\mathrm{H} \mathrm{B}$ & H B & $\mathrm{H} \mathrm{B}$ & $\mathrm{H} \mathrm{B}$ & H B \\
\hline & Impact test & $\triangle$ & $\triangle$ & $\triangle$ & $\triangle$ & $\times$ \\
\hline & Bending test & $\bigcirc$ & $x$ & $x$ & $\triangle$ & $\times$ \\
\hline Alkyd & Conc. of gasolin (\%) & 0 & 16 & 31 & 46 & 66 \\
\hline Linseed medium & Pencil test & $2 \mathrm{H}$ & $2 \mathrm{H}$ & $\mathrm{H}$ & $\mathrm{H}$ & $\mathrm{H} \mathrm{B}$ \\
\hline \multirow[t]{2}{*}{ Clear } & Impact test & $\times$ & $x$ & $\triangle$ & $\times$ & $\times$ \\
\hline & Bending test & 0 & 0 & 0 & 0 & 0 \\
\hline \multirow[t]{4}{*}{ Enamel } & Conc. of gasolin (\%) & 0 & 18 & 36 & 53 & 70 \\
\hline & Pencil test & $\mathrm{H}$ & $\mathrm{H}$ & $\mathrm{H}$ & $\mathrm{H}$ & $\mathrm{H}$ \\
\hline & Impact test & $x$ & $x$ & $x$ & $\times$ & $x$ \\
\hline & Bending test & $x$ & $x$ & $x$ & $\times$ & $x$ \\
\hline Soya long & Conc. of gasolin (\%) & 0 & 18 & 36 & 52 & 72 \\
\hline \multirow[t]{3}{*}{ Clear } & Pencil test & $\mathrm{F}$ & $\mathrm{H} \mathrm{B}$ & $2 \mathrm{~B}$ & $2 \mathrm{~B}$ & $\mathrm{~B}$ \\
\hline & Impact test & $\triangle$ & $\times$ & $\triangle$ & $\triangle$ & $x$ \\
\hline & Bending test & 0 & 0 & 0 & 0 & 0 \\
\hline \multirow[t]{4}{*}{ Enamel } & Conc. of gasolin $(\%)$ & 0 & 20 & 39 & 60 & 80 \\
\hline & Pencil test & $\mathrm{H}$ & $\mathrm{F}$ & H B & $\mathrm{H} \mathrm{B}$ & $\mathrm{B}$ \\
\hline & Impact test & $x$ & $x$ & $x$ & $\times$ & $x$ \\
\hline & Bending test & $\triangle$ & $\triangle$ & $x$ & $\times$ & $\times$ \\
\hline Aminoalkyd & Conc. of gasolin (\%) & 0 & 11 & 20 & 29 & 39 \\
\hline \multirow[t]{3}{*}{ Clear } & Pencil test & $2 \mathrm{H}$ & $2 \mathrm{H}$ & $3 \mathrm{H}$ & $3 \mathrm{H}$ & $3 \mathrm{H}$ \\
\hline & Impact test & $\triangle$ & $\triangle$ & $\triangle$ & $\triangle$ & $\triangle$ \\
\hline & Bending test & $x$ & $\times$ & $\times$ & $\times$ & $\times$ \\
\hline \multirow[t]{4}{*}{ Enamel } & Conc. of gasolin (\%) & 0 & 20 & 40 & 60 & 79 \\
\hline & Pencil test & $2 \mathrm{H}$ & $3 \mathrm{H}$ & $3 \mathrm{H}$ & $2 \mathrm{H}$ & $\mathrm{H}$ \\
\hline & Impact test & $x$ & $\times$ & $x$ & $\times$ & $x$ \\
\hline & Bending test & $x$ & $x$ & $\times$ & $\times$ & $\times$ \\
\hline
\end{tabular}

いるよらに，溶剤の揮発速度の増大にともない検膜の付 着性は一般低下寸ることがわかる。溶剤の揮発速度の 增大にともない，塗装した塗料の不揮発分の上昇速度が 増大して系の粘度が急速に上昇するため, 被塗面に対す るポリマーのヌレ(拡散) が困難になる。このことは被 塗物表面に対するビヒクルポリマーの活性点の配向が困 難になることを意味し, 塗料の被塗物表面への接近を不 十分にし，有效接触面積を減じ付着強さを小さくする。

遊離塗膜の応力〜ひずみ曲線から求めた塗膜バルクの 諸物性に拈よぼす溶剂の揮発速度の影響（図-8）は各試 料とも浪济同じ傾向を示す。すなわち，溶剤の揮発速度 の増大にともない，抗張力は低下し破壊伸び拉よびモジ
ニラスはあまり影響を受けない。このような現象につい てはすで論述されているよう行,2)，溶液中に执ける ポリマーの系まり状態からよく説明できる。

塗料一般試験法に上る耐衝撃特よび耐属曲試験結果か. らは，本実験範囲内の組成の変化にもとづく付着性の評 価は核とんどできない（表-3）。乙かし，測定機構から 予想できることであるが，鉛篻引かき試験からはこの現 象の傾向が比較的明らかにされる。

\section{4. まとめ}

塗膜の付着に扣よぼす溶剤組成の影響を明らかにする 目的で, 典型的溶剂形塗料 3 種 ( $\mathrm{NC}$ ラッカー・アルキ 
ド樹脂塗料・アミノアルキド樹脂塗料）を選び実験を行 なった。溶剤/非溶剂比の異なる一連の試料技よび溶解 力がほぼ等しく揮発速度の異なる 2 種の溶剂を混合した 一連の試料を調製して，付着性との関連を検討した。

付着強さの評価にはアドヘロメーター・ゴン゙ン目招よ び描画試験機を用いた。同時に, Instron 形万能材料試 験機による塗膜の応力〜ひずみ関係測定拉よび JIS-K5400 による塗料一般試験も行なった。

実験結果をまとめると次のようである。

（1）貪溶媒系溶剂組成の塗料泀ど一般に付着性が低 い。この傾向は自然乾燥形塗料（ラッカー括よびアルキ ド樹脂塗料)では顕著であるが, 焼付塗料（アミノアル キド樹脂叙料）では汪とんど認められなかった。

この原因はビヒクルポリマー分子の糸まり状態は良溶 媒系では貪溶媒系のそれに比ベルーズなため，ポリマー
の有効付着活性点の数が増加することと塗料粘度の低下 にとるならヌレの向上と考觉られる。

（2）溶剤の揮発速度の大きい系ほぞ一般に付着性は 低下する。この原因はヌレ現象の低下で説明できる。

(昭和 49 年 10 月 23 日色材協会研究発表会報告)

研究費の一部を提供されたセルロイド硝化綿工業会に 深謝します。

\section{引用文献}

1) W. Funke, U. Zorll : X FATIPEC Congress Book, p. 193 (1970)

2）日比輝義・植木憲二：色材，46，587（1974）

3) N. J. Gribkova et al. : XII FATIPEC Cngress Book, p. 581 (1974)

4）南 誠佑：色材，45，370（1972）

\section{刊行物紹介}

（現代無機化学講座 8）

反応速度之触媒

\author{
田 丸 謙 二編 \\ $15 \mathrm{~cm} \times 21.5 \mathrm{~cm} \quad 278$ 頁 \\ （株）技報堂刊 1,900 円 \\ (昭和 48 年 3 月)
}

“触媒作用” の重要性は広く公知の事実である。この 閒題の本質へのアプローチは，理学・工学の分野をとわ ず極めて重要なことである。本書は，いわゆる教科書的 というょりる，意識的に思考するにはどんなとら方が あるかを主体洼筆されている。すなわち，著者らのそ れぞれの個性的なタッチで記述されている。具体的には つぎ示す本書の構成内容より主旨を理解することがで きよ5。カッユ内若干の記述内容である。

第 1 章 化学反応の速度々機構（全反応速度, 反応速 度式と反応中間体の特徵, 触媒によって促進される反 応，全反応の成り立ち)

第 2 章 触媒反応速度の測定（反応系々速度測定）

第 3 章 固体表面現象の研究方法 (吸着測定法, 電界 顕微鏡, イオン顕微鏡, 分光学・電子分光学的方法)

第 4 章 固体触媒反応飞拈ける吸着と触媒反応の機構 (吸着現象, 反応機構の決定法, 反応中間体之機構）
第 5 章 金属の触媒作用（化学吸着，金属表面と表面 化合物の構造，金属表面飞捛ける反応）

第 6 章 酸化物の触媒作用（酸化物の触媒作用の特 徵, 気体の吸着, 触媒作用々物性, 酸素の活性化とその 反応，炭化水素の選択酸化)

第 7 章 酸塩基触媒作用（固体酸塩基の定義・種類・ 性質・測定法）

第 8 章 金属錯体化よる触媒作用（反応例，特徴）

第 9 章 Electron Donor-Acceptor 錯体化よる触媒作 用 $(\mathrm{EDA}$ 錯体に上る水素交換・添加反応, アンモ $=ア$ 合成，生体反応飞括ける EDA 錯体の役割）

第 10 章 生体触媒（酔素の特徵, 定常状態汇和ける 酵素反応の速度論的解析, 前定常状態飞抢ける醉素反応 の解析, 活性中心, 酵素の構造々活性中心の構造)

以上の上万に，触媒作用全般にわたっての説明がなさ れているので, 基本的な問題点のキャッチには好適書で あろ万。な抢，本書は全体的に及て，理論はるち万几の こと多くの実験データが図・表あるいは式の展開の形で 導入・記述されている点読及やすいと思われる。参考書 的飞利用が望まれる。

(小石真純) 